\title{
Photodynamic Therapy 405 nm Diode Laser as Antibacterial for Cavity and Root Canal Sterilization
}

\author{
Tasya Nafatila Chalisha, ${ }^{1}$ Nadira Nurin Febrianti, ${ }^{1}$ Sri Kunarti, ${ }^{2}$ Setyabudi ${ }^{2}$ \\ ${ }^{1}$ Undergraduate Student of Faculty of Dental Medicine, Airlangga University,Surabaya, Indonesia \\ ${ }^{2}$ Staff of Conservative Dentistry Department, Faculty of Dental Medicine, Airlangga University, Surabaya, Indonesia
}

\begin{abstract}
Background: The goals of caries restoration and endodontic treatment are to repair and prevent the infection from getting worse and if possible, heal the damaged tissue. To achieve this goal, it is necessary to control the presence of microbes in the cavity or root canals with chemo mechanics prior to filling or obturation of the root canals. Disinfection methods using disinfectants with effective bactericidal activity are mostly used at subtoxic levels and at concentrations where their toxicity is a significant factor. In addition, the disinfection method is considered unable to achieve thorough cavity cleaning and causes secondary infection. A new method to provide better disinfection without cytotoxic effects has recently been discovered using the photodynamic method of $405 \mathrm{~nm}$ diode laser therapy. Research continues and is progressing with the existence of various factors that affect the effectiveness of the 405nm diode laser as an antibacterial. Purpose: To evaluate the results of research on photodynamic diode laser therapy with a wavelength of $405 \mathrm{~nm}$ as a combination antibacterial therapy in cavity and root canal sterilization techniques. Review(s): Literature study in the form of narrative review using libraries obtained through the PubMed and Google Scholar databases. The optimal bacterial mortality was influenced by the form factor of the target bacteria, the energy dose and duration of laser exposure, and the type of photosensitizer used. Conclusion: The use of a $405 \mathrm{~nm}$ diode laser with an energy power of $50 \mathrm{~mW}$ with a distance of $20 \mathrm{~mm}$ can degrade biofilms Streptococcus mutans up to 100\% using erythrosine photosensitizer, for 75 seconds. And with the same power and distance, it can degrade the biofilm of bacteria Enterococcus fecalis up to 97.51\%, using a photosensitizer chlorophyll, for 120 seconds.
\end{abstract}

Keywords: Antibacterial; Photodynamic therapy; $405 \mathrm{~nm}$ diode laser; Photosensitizer

Correspondence: Sri Kunarti, Conservative Dentistry Department, Faculty of Dental Medicine, Universitas Airlangga. J1 Mayjen. Prof. Dr. Moestopo No.47, Surabaya 60132, Indonesia. Email: sri-k@fkg.unair.ac.id

\section{INTRODUCTION}

Streptococcus mutans (S. mutans) and Lactobacillus acidophilus (L. Acidophilus) are the most important bacterial colonies that are responsible for the occurrence of dental caries, and S. mutans is considered the main cariogenic organism. Staphylococcus aureus is one of the causes of root canal infections and is a persistent facultative anaerobic bacterium. According to Yamin et al., 2014 Staphylococcus aureus bacteria were found in $20 \%$ of the root canals of necrotic teeth ${ }^{1}$. Secondary infection post endodontic treatment can also lead to endodontic failure ${ }^{2}$. Several studies have shown that Enterococcus faecalis is more common in cases of endodontic treatment failure. Among all reported cases of pain and post endodontic therapy infection, it was observed that E. faecalis was the most common, with a high prevalence rate of up to $90 \%$.

Cleaning of the cavity before filling and sterilizing the root canals before obturation in endodontics was carried out by applying disinfectant material. Chlorhexidine is known as the gold standard for antibacterial agents as a disinfectant cavity, and sodium hypochloride as the gold standard for root canal irrigation ${ }^{3}$. Antibacterial chemical agents can help reduce the number of pathogenic bacteria. However, this prevention method cannot cover the entire population so that the tooth cavity is still formed ${ }^{4}$. In addition, most of the disinfection methods that use disinfectants with effective bactericidal activity are used at sub-toxic levels, and at concentrations where toxicity is an important factor ${ }^{5}$.

Given the shortcomings of disinfectants for cavity and root canal sterilization, a tool was developed that provides better disinfection without cytotoxic effects using the photodynamic method of laser therapy. Laser is an acronym for Light Amplification by Stimulated Emission of Radiation. There have been many studies examining the effectiveness of lasers as anti-bacterial tools in caries and root canals. Photodynamic Therapy (PDT) disinfectant method which was studied is known as Photo Activated Disinfection (PAD). Diode lasers are currently being researched for their use as PDT in their function as an

https://e-journal.unair.ac.id/CDJ 
antibacterial, one of the most common is violet blue light which is the diode laser. The antimicrobial effect of violetblue light with peak activation power is at a wavelength of $405 \mathrm{~nm}$. This absorption of light by the laser is carried out using endogenous porphyrin resulting in the production of reactive oxygen species, including $\mathrm{H}_{2} \mathrm{O}_{2}$ and singlet oxygen, which cause oxidative damage and cell death.

This review article is to summarize the recent developments regarding the photodynamic therapy (PDT) of $405 \mathrm{~nm}$ wavelength diode laser in dentistry especially for cavity disinfection of caries and root canals in endodontic treatment.

\section{REVIEW(S)}

Photodynamic Therapy (PDT) is a form of phototherapy that involves light, photosensitizing chemicals, and molecular oxygen, resulting in cell death (phototoxicity). PDT has the proven ability to kill microbial cells, including bacteria, fungi, and viruses ${ }^{6}$. Photo-activated disinfection (PAD) is a disinfection method that uses a photosensitization application and then irradiates it with a laser ${ }^{7}$. The antimicrobial effect of the laser violet-blue has been investigated using a wavelength in the $400-420 \mathrm{~nm}$ region, with peak activation power shown at $405 \mathrm{~nm}^{8}$.

Photodynamic therapy is based on the use of a combination of a photosensitizer and a suitable visible light wavelength to form free radicals or superoxide ions from the transfer of hydrogen or electrons producing reactive oxygen species (ROS). ROS will react with the surrounding molecules and exert a bactericidal effect on the target microorganisms ${ }^{4}$. Photosensitizer has the ability to absorb specific light. The photosensitizer's ability depends on a specific wavelength of light emitted to cause bacterial cell death.

Photosensitization oxidation is the basis for photodynamic reactions. PDT involves three main components, namely light, photosensitizer, and oxygen. The first step in this reaction is the absorption of light by the sensitizer to produce an excited sensitizer state. In the presence of oxygen, two reactions (reacting with the substrate or solvent (Type I) or with oxygen (Type II)) of an excited sensitizer state can occur. The excited sensitizer then turns into a triplet sensitizer via the mechanism intersystem crossing (ISC). Triplet state photosensitizer can react via Type-I and Type-II processes. Type I reactions involve an electron transfer reaction between the excited state of the photosensitizer and the molecules of the cell's organic substrate, producing free radicals ${ }^{9}$. Singlet oxygen can interact with many biological substrates inducing oxidative damage to cell membranes and cell walls of bacteria, viruses and fungi ${ }^{10}$.

Photodynamic therapy as an anti-bacterial therapy is based on exogenous compounds photosensitizer that will bind to pathogenic bacteria. Anionic surface in bacteria acts as an electro-attractive to the photosensitizer cationic, thereby causing photosensitizer more efficiently bound and entry into bacteria ${ }^{11}$. Photosensitizer which has tied up with the bacteria will cause electrostatic interactions between the photosensitizer and the bacterial cell wall that ion release of $\mathrm{Ca}^{2+}$ and $\mathrm{Mg}^{2+}$ out of the cell so that the permeability of the wall bacterial cell increased ${ }^{5}$. The increase in permeability of the bacterial wall will cause the photosensitizer to diffuse into the plasma membrane and the cytoplasm of the bacteria.

Apart from the use of a photosensitizer, another determining factor is the radiation energy dose. The right dose of energy activates chemical reactions that produce various ROS resulting in death in bacteria. The laser irradiation energy dose per total irradiated area (power density, units $\mathrm{J} / \mathrm{cm}^{2}$ ) is the amount of radiation energy (power multiplied by longer exposure time) divided by the total area of irradiation. This determines the duration of the laser irradiation time adjusted to the energy dose and quantum yield of the laser used ${ }^{12}$.

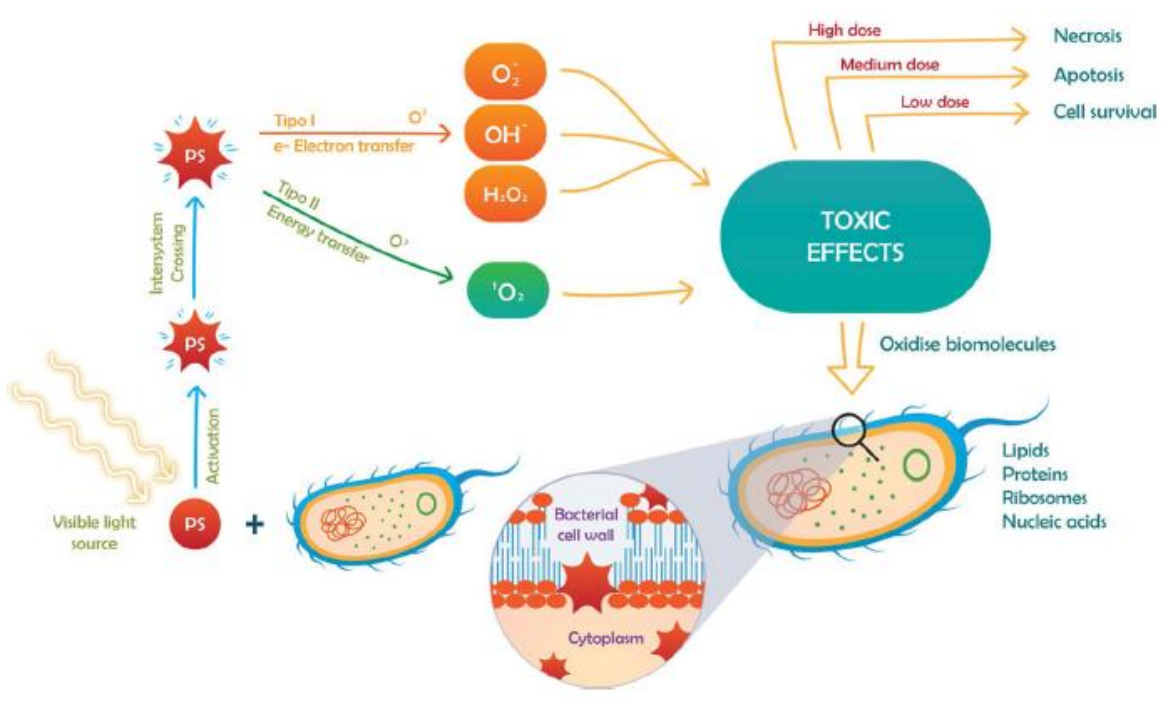

Figure 1. Schematic of the antibacterial mechanism of photodynamic therapy ${ }^{9}$. 


\section{DISCUSSION}

Photodynamic antibacterial therapy using a diode laser with a wavelength of $405 \mathrm{~nm}$ is a photodynamic therapy currently being developed for combined antibacterial therapy in cavity and root canal sterilization. There are several factors that must be considered for the $405 \mathrm{~nm}$ diode laser to be the antibacterial therapy with the most effective potential. Streptococcus mutans (S. mutans), Lactobacillus acidophilus (L. Acidophilus), Enterococcus faecalis (E. Faecalis), and Staphylococcus aureus (S. aureus) discussed in this literature are some of the bacteria that most play a role in caries, and the microorganisms that resistant and survivable in root canals after biomechanical preparation leading to failure of endodontic treatment.

Three basic components are needed in a photodynamic reaction, namely a photosensitizer in the form of a photosensitive molecule that can localize itself in the cell or in the target tissue, a light source with a certain wavelength needed to activate the photosensitizer, and molecular oxygen which is essential for the formation of reactive oxygen species (ROS). The energy dose is directly proportional to the exposure time used, the more the exposure time is given, the higher the energy dose generated from the $405 \mathrm{~nm}$ diode laser. The energy dose of $20 \mathrm{~J} / \mathrm{cm}^{2}$ can kill Streptococcus mutans bacteria as much as $61.9 \%{ }^{13}$. In 2016, with the higher dose Astuti use energy dose of $25,34 \mathrm{~J} / \mathrm{cm}^{2}$ with a time of 75 seconds, was able to kill the bacteria Streptococcus mutans as much as $74.03 \%$ using photosensitizer chlorophyll ${ }^{14}$. An increase in the number of bacterial deaths resulted by increasing the energy dose to $30 \mathrm{~J} / \mathrm{cm}^{2}$ and the exposure time increased to 150 seconds resulted in a higher percentage of bacterial death, namely $99.26 \%$ using photosensitizer curcumin ${ }^{15}$. For bacteria Staphylococcus aureus, the energy dose generated from 120 seconds of exposure time, amounting to $22.56 \mathrm{~J} / \mathrm{cm} 2$ can kill Staphylococcus aureus bacteria with a percentage of $55.22 \%{ }^{16}$. With a lower energy dose of $16.19 \mathrm{~J} / \mathrm{cm} 2$ and with the same exposure time it can kill as much as $91.49 \%$. From these results it can be said that the ideal energy dose is not always the highest energy dose, because optimal bacterial death does not always use the highest energy dose.

The light source from the laser has an energy intensity related to the power per unit area of laser exposure. The intensity of the diode laser exposure indicates the number of photons emitted, and the laser energy dose represents the intensity that the laser produces in a certain time. More power with a small surface area results in a greater intensity. The greater energy density / laser diode dose, the more high-energy photons can absorb by photosensitizer molecule. The greater the photon intensity and the longer the exposure time, the more photosensitizer is activated to produce various ROS which affect the number of bacterial deaths. The photosensitizer used in the $405 \mathrm{~nm}$ diode laser therapy will be optimal only when the photosensitizer is used in accordance with the $405 \mathrm{~nm}$ wavelength spectrum. Bactericidal effect of laser diodes views of the susceptibility of bacteria to laser exposure to certain wavelengths when combined with photosensitizer the appropriate ${ }^{15}$.

The susceptibility of bacteria to PDT differs according to PS type even for the same bacterial strain. Bacteria were Streptococcus mutans found to be susceptible to the photosensitizer curcumin and photo porphyrin IX, and not susceptible to riboflavin and resazurin ${ }^{17}$. The percentage of bacteria death $S$. mutans can reach $99.26 \%$ by using the photosensitizer curcumin ${ }^{15}$. Meanwhile, by using chlorophyll, bacterial mortality can be achieved up to $74 \%{ }^{14}$. The bacterial mortality $S$. mutans most optimal is achieved by using erythrosine as a photosensitizer which can produce the bacteria death by $S$. mutans most up to $100 \%$, so it can be said that erythrosine is photosensitizer the most effective for bacteria $S$. mutans by using a $50 \mathrm{~mW}$ laser power for 75 seconds $^{18}$. The use of photosensitizer chlorophyllin PDT can degrade the biofilm which Enterococcus faecalis can achieve bacterial death up to $97.51 \%{ }^{19}$, degradation of biofilm Staphylococcus aureus as much as $98 \%{ }^{20}$ and in biofilm Lactobacillus acidophilus which can kill $99.33 \%{ }^{21}$.

The resistance of bacteria in biofilms is known to be more resistant to the presence of antimicrobial therapy than planktonic microorganisms. The interaction of molecules photosensitizer and Extracellular Polymeric Substance matrix (EPS) even without a light source can affect the cohesion and stability of the EPS matrix, causing polysaccharide damage to the EPS matrix. However, after applying a light source, the polysaccharide level was considerably reduced by $80 \%{ }^{22}$. Research conducted by Astuti et al., 2016, stated that a $405 \mathrm{~nm}$ diode laser against planktonic bacteria can reduce the number of planktonic bacteria $S$. mutans by $74 \%$ in just 75 seconds with a photosensitizer chlorophyll ${ }^{14}$. As for the percentage of EPS degradation, the biofilm bacteria S. mutans reached 98\% with a longer exposure time of 120 seconds $^{23}$. With the same exposure time of 120 seconds, it showed degradation of the EPS biofilm Staphylococcus aureus a significant $98 \%{ }^{20}$. So, it can be said, it is possible that if planktonic bacteria are $S$. mutans given the same laser exposure as biofilms for 120 seconds it can produce more optimal mortality than biofilm death $S$. mutans, because in just 75 seconds planktonic bacteria can kill as much as $74 \%$. Likewise, the death of the planktonic bacteria Enterococcus faecalis which was given exposure to a $405 \mathrm{~nm}$ diode laser with chlorophyll was able to kill bacteria up to $81.29 \% \%^{24}$. Enterococcus faecalis bacteria which form a biofilm when given chlorophyll and irradiated with a $405 \mathrm{~nm}$ diode laser can degrade EPS biofilms up to $97.51 \%{ }^{19}$. Degradation of the bacterial biofilms obtained greater results probably due to the different duration of laser irradiation, 120 seconds on biofilms and 60 seconds for planktonic bacteria.

Photodynamic therapy using a photosensitizer can reduce the number of bacteria in the form of biofilms less than planktonic bacteria, this is possible because of the heterogeneity of biofilms, limited penetration of microbial agents penetrating material extracellular matrix, decreased cell growth in biofilms, and differences inexpression 
genetic on biofilms ${ }^{25}$, and the biofilm has the strength of the supporting network and resistance to antimicrobial substances ${ }^{26}$.

Photosensitizer cationic is more effective against bacteria than the photosensitizer anionic, due to adhesions and uptake photosensitizer anionic by the cells of the bacteria is lower than photosensitizer cationic ${ }^{27}$. Cationic molecules carry a positive charge on their functional groups, so they are easily bound and taken up by bacteria that have a negative charge on the surface ${ }^{28}$. In addition to the type of photosensitizer, photodynamic antibacterial therapy is more effective in killing gram-positive bacteria because the outer wall layer of the bacteria contains peptidoglycan and lipoteichoic acid, making it more porous and will make it easier for the photosensitizer to penetrate the plasma membrane ${ }^{29}$.

The peak absorption of the erythrosine photosensitizer is at a wavelength of $532 \mathrm{~nm}^{30}$. Research that has been done says that a $405 \mathrm{~nm}$ diode laser with erythrosine photosensitizer can kill bacteria Streptococcus mutans with a percentage of $100 \%{ }^{18}$. The use of erythrocyte photosensitizer was also carried out by Merigo et al., 2019 against bacteria Streptococcus mutans which can also result in total death of $100 \%$ bacteria $^{15}$. The mortality results obtained, in conditions without erythrosine irradiation, were able to show a bacterial inhibiting effect up to $82 \%$ compared to negative controls.

The absorption spectrum of chlorophyll as a photosensitizer at a wavelength of $300-900 \mathrm{~nm}$ was measured from a UV-Vis spectrophotometer with the percent absorption of chlorophyll at a wavelength of $405 \mathrm{~nm}$ (laser diode) of $99.51 \%{ }^{14}$. Chlorophyll as a photosensitizer with $405 \mathrm{~nm}$ diode laser irradiation showed the most optimal results in the use of a $405 \mathrm{~nm}$ laser on biofilm Lactobacillus acidophilus which killed 99.33\% $\%^{21}$. Meanwhile, the percentage of death of the bacteria Streptococcus mutans was $98 \%{ }^{23}$, and against the bacteria Enterococcus faecalis was $97.51 \%{ }^{19}$.

The best absorption of curcumin is in the region of 420-450 nm. With $405 \mathrm{~nm}$ LED irradiation, curcumin showed antibacterial activity even at low concentrations ${ }^{31}$. The susceptibility of bacteria was Streptococcus mutans shown by administering a $405 \mathrm{~nm}$ laser with photosensitizer curcumin and protoporphyrin $\mathrm{IX}^{17}$. Diode laser with a wavelength of $405 \mathrm{~nm}$ applied with a photosensitizer curcumin can kill the most optimal bacteria, namely Streptococcus mutans up to $99.26 \%{ }^{15}$.

In its ability to kill bacteria, $405 \mathrm{~nm}$ diode laser photodynamic therapy influences the surrounding tissue. Research conducted by Ramakrishnan et al., 2014 showed that exposure of bacterial cells to laser light $405 \mathrm{~nm}$ up to a dose of $36 \mathrm{~J} \mathrm{~cm}^{2}$ did not cause detectable damage to cell viability, function, proliferation rate, and morphology in mammalian cells ${ }^{32}$, and remained can cause a significant bactericidal effect. Exposure period of more than 2 hours at a radiation level $5 \mathrm{~mW} / \mathrm{cm} 2\left(>36 \mathrm{~J} / \mathrm{cm}^{2}\right)$ is toxic to cells that cause cell function and cell death, in other words the higher doses, there is a negative impact on cell viability, function, and the rate of cell proliferation. In addition, the viability test on the $405 \mathrm{~nm}$ diode laser was carried out by Nizar et al., 2020 using BHK-21 cell culture from fibroblasts, it was found that more than $80 \%$ of the viability of fibroblast cells after exposure to the $405 \mathrm{~nm}$ diode laser at a distance of 7 $\mathrm{mm}, 10 \mathrm{~mm}, 13 \mathrm{~mm}$, and $16 \mathrm{~mm}$. Whereas in the treatment with a distance of $4 \mathrm{~mm}$, the results showed that there was an increase in the number of fibroblast cells, although not too significant, namely by $4.09 \%{ }^{33}$.

In addition to time variations, the use of diode lasers with time variations used to see cell viability showed that the irradiation time of $30,60,120$, and 240 seconds had no effect on the viability of BHK-21 fibroblast cells, this happened because the cell chromophore did not absorb enough energy of photons to stimulate the biological activity of the cell. In the 480 second treatment, the viability of BHK-21 fibroblast cells increased by $12.1 \%$. With a time of 480 seconds, the energy absorbed by the cell is sufficient to stimulate the biological activity of the cell to allow a $405 \mathrm{~nm}$ diode laser bio stimulation response, resulting in an increase in BHK21 fibroblast cells ${ }^{34}$.

\section{CONCLUSION}

Bacterial biofilms of Streptococcus mutans and Enterococcus faecalis are the most virulent bacterial colonies associated with caries and failure of endodontic treatment. The use of a $405 \mathrm{~nm}$ diode laser with an energy power of $50 \mathrm{~mW}$ with a distance of $20 \mathrm{~mm}$ can degrade biofilms Streptococcus mutans up to $100 \%$ using erythrosine photosensitizer, for 75 seconds. And with the same power and distance, it can degrade the biofilm of bacteria Enterococcus faecalis up to $97.51 \%$, using a photosensitizer chlorophyll, for 120 seconds.

\section{ACKNOWLEDGEMENTS}

We thank Dr. Widya Saraswati, drg., M. Kes., Sp. KG (K), Nanik Zubaidah, drg., MS., Sp. KG (K), Dr. Dian Agustin Wahjuningrum, drg., Sp. KG (K), Ferindra Irawan, ST., and Jael Segah Mahamiano Ludjen for their assistance with data collection.

\section{REFERENCES}

1. Yamin IF, Natsir N. Bakteri Dominan di dalam Saluran Akar Gigi Nekrosis. Dentofasial. 2014; 13(2): 113-116.

2. Pereira RS, Rodrigues VVA, Furtado WT, Gueiros S, Pereira GS, Avila-Campos MJ. Microbial analysis of root canal and periradicular lesion associated to teeth with endodontic failure, Anaerobe. 2017; 1-24.

3. Iqbal A. Antimicrobial Irrigants in the Endodontic Therapy. International Journal of Health Sciences. 2012; 6(2): 153-8.

4. Paschoal M, Tonon C, Spolidório D, Bagnato V, Giusti J, Santos-Pinto L. Photodynamic potential of curcumin and blue LED against Streptococcus mutans in a planktonic 
culture. Photodiagnosis and Photodynamic Therapy. 2013; 10(3):313-319.

5. Diogo. P, Gonçalves T, Palma P, Santos J. Photodynamic Antimicrobial Chemotherapy for Root Canal System Asepsis: A Narrative Literature Review. International Journal of Dentistry. 2015; 1-26.

6. Saini R, Lee N, Liu K, Poh C. Prospects in the Application of Photodynamic Therapy in Oral Cancer and Premalignant Lesions. Cancers. 2016; 8(9): 83.

7. Johar K. Fundamentals of Laser Dentistry. New Delhi. Jaypee Brothers Medical Publishers (P) Ltd. 2011. Pp: 134-7.

8. Gillespie JB, Michelle M, Given MJ, Wilson MP, Judd MD, Timoshkin IV, MacGregor SJ. Efficacy of Pulsed 405-nm Light-Emitting Diodes for Antimicrobial Photodynamic Inactivation: Effects of Intensity, Frequency, and Duty Cycle. Photomedicine and Laser Surgery. 2017; 35(3): 150-5

9. Reis A. C. M., W. F. M. Regis, L. K. A. Rodrigues. Scientific Evidence in antimicrobial photodynamic therapy: An alternative approach for reducing cariogenic bacteria. Photodiagnosis and photodynamic therapy. 2019; 29: 179189.

10. Rajesh S, E. Koshi, K. Philip, A. Mohan. Antimicrobial Photodynamic Therapy: An Overview. Journal of Indian Society of Periodontology. 2011; 15(4): 323-327.

11. Liu, Y., R. Qin, S. A. J. Zaat, E. Breukink, and M. Heger. . Antibacterial photodynamic therapy: overview of a promising approach to fight antibiotic-resistant bacterial infections. Journal of Clinical and Translational Research, 2015; 1(3): 140-167.

12. Astuti S. D. An in-vitro antimicrobial effect of $405 \mathrm{~nm}$ laser diode combined with chlorophylls of Alfalfa (Medicago sativa L.) on Enterococcus faecalis. Dent. J. (Majalah Kedokteran Gigi). 2018; 51(1): 47-51.

13. Astuti S. D., S. A. Sunarko, W. Ekasari. Antimicrobial effect of pleomeleangustifolia pheophytin A activation with diode laser to streptococcus mutans. IOP Conf. Series: Journal of Physics. 2017; 853: 1-6.

14. Astuti S. D., A. Zaidan, E. M. Setiawati, Suhariningsih. Chlorophyll mediated photodynamic inactivation of blue laser on Streptococcus mutans. AIP Conference Proceedings. 2016; 1718: 120001-1-8.

15. Merigo E., S. Conti, T. Ciociola, M. Manfredi, P. Vescovi, C. Fornaini. Antimicrobial Photodynamic Therapy Protocols on Streptococcus mutans with Different Combinations of Wavelengths and Photosensitizing Dyes. Bioengineering. 2019; 6(42): 1-10.

16. Astuti S. D., I. W. Widya, D. Arifianto, R. Apsari. Effectiveness Photodynamic Inactivation with Wide Spectrum Range of Diode Laser to Staphylococcus aureus bacteria with endogenous Photosensitizer. Journal of Internatonal Dental and Medial Research. 2019; 12(2): 481-486.

17. Kang S. M., H. Jung. Kim B. Susceptibility of Oral Bacteria to Antibacterial Photodinamic Therapy. Journal of Oral Microbiology. 2019; 11: 1644111.

18. Kunarti S., A. Dita, W. Saraswati. The Duration Effectivity of Diode Laser $405 \mathrm{~nm}$ with Erythrosine Photosensitizer in Killing Streptococcus Mutans. Conservative Dentistry Journal. 2020; 10(1): 1-4.

19. Santoso M L. Degradasi Extracellular Polymeric Substance Biofilm Enterococcus faecalis Akibat Lama Paparan Laser Diode 405nm. Repository Universitas Airlangga. Surabaya. 2018

20. Sudjarwo K E. Degradasi Extracellular Polymeric Substance (EPS) Biofilm Bakteri Staphylococcus aureus Akibat Waktu Paparan Laser Diode Panjang Gelombang 405nm dengan
Fotosensitizer Klorofil. Repository Universitas Airlangga. Surabaya. 2018.

21. Ruslan M I. Degradasi Extracellular Polymeric Substance (EPS) Biofilm Lactobacillus acidophilus Akibat Waktu Paparan Laser Diode $405 \mathrm{~nm}$ dan Fotosensitiser Klorofil. Repository Universitas Airlangga. Surabaya. 2018.

22. Hu X, Huang Y, Wang Y, Wang X, Hamblin M. R. Antimicrobial Photodynamic Therapy to Control Cinically Relevant Biofilm Infection. Frontiers in Microbiology. 2018; 9(1299): 1-24

23. Tasniadara I. Degradasi Extracellular Polymeric Substance Biofilm Bakteri Streptococcus mutans Akibat Paparan Laser Diode 405nm. Repository Universitas Airlangga. Surabaya. 2018.

24. Tjandra A, Kunarti S, Prasetyo EA. Efficacy of Diode Laser $450 \mathrm{~nm}$ with Chlorophylls as Photosensitizer on Enterococcus Faecalis. Conservative Dentistry Journal. 2018; 8(2). Pp : 31-35

25. Freire F.C., A. C. B. Pereira, Pereira, C. Aparecida; B. Junior, Milton, Junqueira, J. Campos, Jorge, A. O. Cardoso. Comparison of the effect of rose bengal- and eosin Y-mediated photodynamic inactivation on planktonic cells and biofilms ofCandida albicans. Lasers in Medical Science. 2014; 29(3), 949-955.

26. Street, Cale N.; Pedigo, Lisa A.; Loebel, Nicolas G. (2010). Energy Dose Parameters Affect Antimicrobial Photodynamic Therapy-Mediated Eradication of Periopathogenic Biofilm and Planktonic Cultures. Photomedicine and Laser Surgery. 2010; 28(S1), S-61-S-66.

27. Pereira CA, Costa AC, Carreira CM, Junqueira JC, Jorge AO. Photodynamic inactivation of Streptococcus mutans and Streptococcus sanguinis biofilms in vitro. Lasers Med Sci. 2013; 28(3):859-64.

28. Ghorbani J., R. Dariush, A. Shahin, T. Alireza, B. Abbas. Photosensitizers in antibacterial photodynamic therapy: an overview. Laser Therapy. 2018; 27(4): 293-302.

29. Carrera, E T; Dias, H B; Corbi, S C T; Marcantonio, R A C; Bernardi, A C A; Bagnato, V S; Hamblin, M R; Rastelli, A N S. The application of antimicrobial photodynamic therapy (aPDT) in dentistry: a critical review. Laser Physics, 2016; 26(12), 123001.

30. Silva, A.F.; Borges, A.; Freitas, C.F.; Hioka, N.; Mikcha, J.M.G.; Simões, M. Antimicrobial Photodynamic Inactivation Mediated by Rose Bengal and Erythrosine Is E_ective in the Control of Food-Related Bacteria in Planktonic and Biofilm States. 2018; 23, 2288.

31. Lee H. J., S. M. Kang, S. H. Jeong, K. H. Chung, B. Kim. Aantibacterial Photodynamic Therapy With Curcumin and Curcuma Xanthorrhiza Extract Against Streptococcus mutans. Photodiagnosis and Photodynamic Therapy. 2017; 1-14.

32. Ramakrishnan P., M. Michelle, M. Scott J, A John G., M. H. Grant. Differential sensitivity of osteoblasts and bacterial pathogens to $405-\mathrm{nm}$ light highlighting potential for decontamination applications in orthopedic surgery, 2014; 19 (10), 105001.

33. Kunarti S., V. Z. Nizar, W. Saraswati. Viability Test of Photodynamic Therapy with Diode Laser Waves Length 405 nm on BHK-21 Fibroblast Cells with Various Irradiation Distances. Conservatve Dentistry Journal. 2020; 9(2): 8286

34. Ismiyatin K, L. H. Rumbiak, W. Saraswati, S. Kunarti, A. Bhardwaj. Pengaruh Variasi Lama Laser Dioda 405nm Terhadap Viabilitas Sel Fibroblas BHK-21. Conservative Dentistry Journal. 2019; 9(1). Pp: 13-8 